\title{
全自動錠剤分包機に関する基礎研究 \\ 幾何学的解析法による硬カプセルの大きさとフィーダー落下穴の寸法との関係*1
}

\author{
金井三良, 近藤由利子, $* 2$ 野呂俊一*3 \\ 東邦大学医学部附属大森病院薬㓣部, $* 2$ 明治薬科大学 $* 3$
}

\author{
Study on the Automatic Tablet Packaging Machine : \\ Geometric Analysis for the Correlation of the Size of the Hard Gelatin \\ Capsules to That of Drop Holes \\ in Capsule Supply Apparatus*1
}

\author{
SABURO KANAI, YURIKO KONDO*2 and SHUNICHI NORO*3 \\ Pharmacy, Toho University School of Medicine, *2 Meiji College of Pharmacy*3
}

(Received March 6, 1984)

\begin{abstract}
The correlation between the size of commercial capsules and that of drop holes of the capsule supply apparatus was studied by a geometric analysis on automatic tablet packaging machine (type OMP-CAT-150). The following results were obtained from the calculation of the sizes of capsules and drop holes : 1) Suitable ranges of length and diameter of capsules were formularized under the setting of constant height and diameter of drop holes, as follows :

$$
\{(8-2 \sqrt{6}) / 5\} \cdot b<B<b-\sqrt{2 b \cdot B-b^{2}}+B / 2+a<A<a
$$

where $\mathrm{A}, \mathrm{B}, \mathrm{a}$ and $\mathrm{b}$ are capsule length, capsule diameter, drop hole height and hole diameter, respectively. 2) Commercial capsules are classified into six groups by their size. It can, therefore, be expected that the automatic tablet packaging machine is miniaturized by reducing the varieties of capsule supply apparatus.
\end{abstract}

Keywords - hard gelatin capsules; automatic tablet packaging machine ; size of drop holes of capsule supply apparatus ; geometric analysis; length and diameter of capsules

医療の場としての病院は,診療の高度化, 能率化, 円滑 化，あるいは患者へのサービスなどに益々力をそそぐ必 要がある．その中で病院薬局も業務の合理化をはかり， 病院や患者にメリットとなる仕事が望まれている.

現在の病院薬局業務の中で重要な計数調剂工程に, 全 自動錠剤分包機が導入されつつあり, この機械により, 患者が薬剂を誤りなく服用するための最も確実な投与方 法である 1 回量包装（すべての錠剤を 1 回服用量每に分 包する方法）を自動的に行らことができる.1 6)

*1 本報は日本薬学会第99年会(札幌市, 1979年 8 月) で発表.

*2 東京都大田区大森西 6 丁目 11-1 ; 11-1, Omori Nishi 6-chome, Ota-ku, Tokyo, 143 Japan

*3 東京都世田谷区野沢1丁目35-23；35-23, Nozawa 1-chome, Setagaya-ku, Tokyo, 154 Japan
しかしながら，現在市販の全自動錠阂分包機は多品目 の錠剤およびカプセル剤の分包機能開発にのみウェイト がおかれており, 薬学研究の立場から, 全自動錠剤分包 機が医薬品の基礎的物性にどのように影響するかという 研究は少ない.2)

錠剂およびカプセル剂の形状, 寸法, 重量, 硬度, 磨 損度, 崩壊時間, さらに環境条件による主薬の安定性の 変化は，分包機により影響を受ける.7 したがって，分包 機作動時の機械的条件と医薬品の物性との関係を把握し ておくことは非常に重要である.8 10)なかでも, 錠剤およ びカプセル剂の形状，寸法に影響するフィーダーは，そ の選択方法に理論的裹付けがなく，メーカー側の経験則 に基づて多種類作製され，新規製剤への対応，経済面 で問題がある．またこのような多種類のフィーダーを内 
蔵するには機械る大型化せざるを得ない.11) この現状を 考え，まず市販硬カプセル剤の大きさとフィーダー落下 穴の寸法との関係を幾可学的解析により求めた. そして 将来, ニーザー自身が容易にフィーダーを選択でき, 全 自動錠剤分包機を小型化する方向への指針となるよう 二, 三の実験的考察を行った.

\section{実 験 の 部}

\section{1. 実験装昷}

\section{1-1. 全自動錠郕分包機 (OMP-CAT-150)}

今回使用した全自動錠剤分包機（東商式, OMP-CAT -150）装置の本体を Fig. 1 亿示した. 㭗品収納供給部, SP (special) コンベアーバスケット部および包装機構部 の3 部より構成されている.

薬品收納供給部は特殊ロータリ一設計の錠剂フィーダ ー 150 本を収納し, 送り出し検出器を内蔵した自動装置 である. S P コンベアーバスケット部は軟カプセル刻ま たは服用時刻により薬品分量の異なる薬品を，本体供給 部にあらかじめ準備した薬品と同時に送り出すことので きる装置である.包装機構部は薬品収納供給部护よび $\mathrm{S}$ P ンンベアーバスケット部の両方またはどちらか一方か ら送り出された薬品を，一度その下方にあるホッパーに 集め, 1 回服用量毎につぎつぎと包装し機外へ送り出す 装置である.

以上の本体以外飞, 付属部として操作機構部があり, 本体に叔ける薬品の送り出しから検出，包装に至る諸動
作をすべてコントロールするコンピューターを内蔵して いる、したがって，オペレーターはきわめて簡単なキー 操作だけで 1 回量包装作業を行うことが可能である.

\section{1-2. カプセル用フィーダー}

Fig. 2 亿薬品供給器の一種で, 全自動錠剂分包機の本 体内部に設置されているカプセル用フィーダーの構造を 示した.フィーダー内部はカプセルが縦に 1 個ずつ入る 直方体の分画が円周方向に形成されている．その分画を 形成するフィーダー円盤が主軸を中心に平面上を回転運 動し, カプセル落下穴に一致した時, 上方のカプセルと 選別, 分級され必ず 1 回に 1 個ずつ落下するように設計 されている，ロータリー方式といわれる供給方法を採用 したこの装置は, 単にフィーダー落下穴の寸法を調節す るだけで，すべての市販硬カプセルに適合し，供給が正 確で固形剂淢械的損傷を与えにくい特 長をもってい る.

\section{2. 実験法}

市販の硬カプセル剤の大きさとフィーダー落下穴の寸 法との関係を検討するため, 当病院に採用されている硬 カプセル剂55品目について，同一ロット番号の製品から 無作為に10個を抽出し，ノギスを用いてそのボディーの 長さ拉よび直径を精密に測定し, 平均值と標準偏差を求 めた。ささらに, 現在使用中のフィーダーについて, 落下 穴の高さおよび内径を精密に測定した。

3. カプセルの大きさとフィーダー落下穴の寸法との 関係についての幾可学的解析

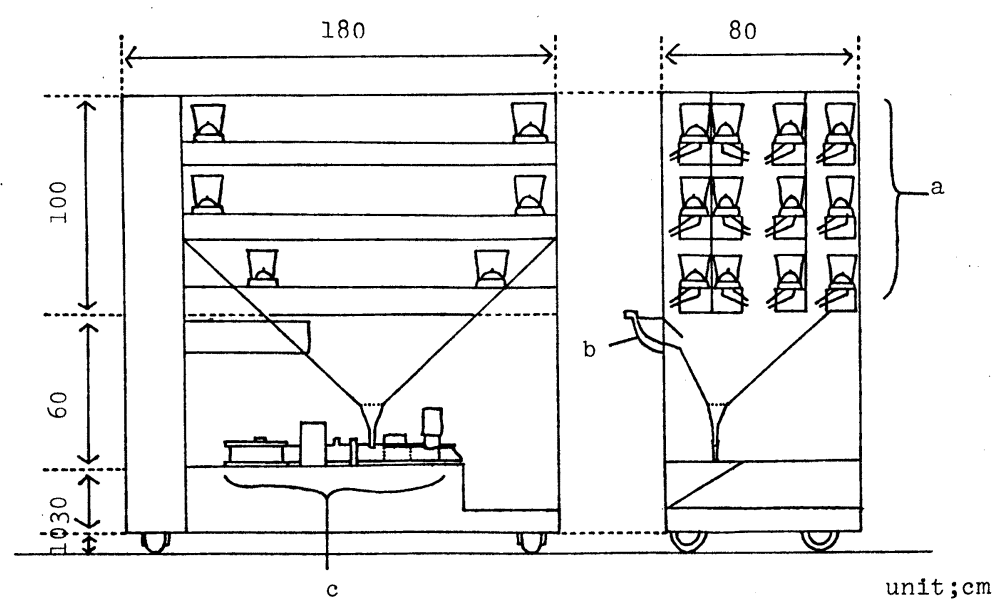

Fig. 1. Schematic Diagram of Automatic Tablet Packaging Machine (type Tousho OMP-CAT-150)

a : Sections of Receipt and Supply with Drugs

b : SP Conveyor Basket

c : Section of Pack 


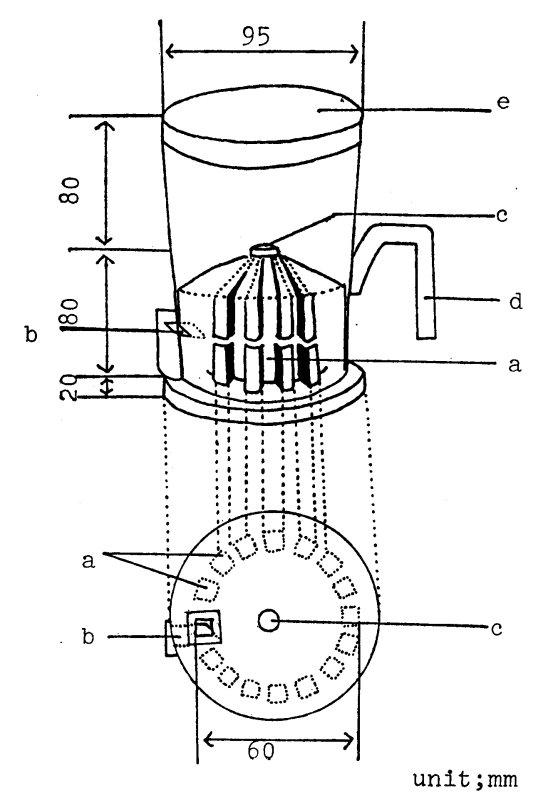

Fig. 2. Cross Sectional Diagram of Capsule Supply Apparatus

a : Drop Holes b : Cutter

c : Spindle d: Catch

e : Cover

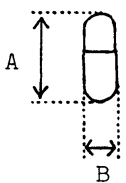

(I)

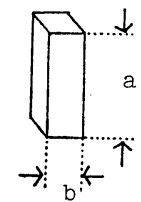

(II)

Capsule Drop Hole

Fig. 3. Schematic Illustration of Capsule and Drop Hole
A : Length
B : Diameter
a : Height
b : Diameter

カプセルがフィーダー落下穴に 1 回に 1 個だけ入り, 通過する条件を幾可学的に理論解析する.この際, 1) カプセルの大きさがきまっている場合，2）フィーダー 落下穴の大きさがきまっている場合，の両面から解析す る.

\section{3-1. カプセルに適合するフィーダー落下穴寸法範囲 の算出}

Fig.3 に, カプセルボディーの長さ(A) と直径(B), およびフィーダー落下穴の高さ(a)と内径(b)を示した.

フィーダー落下穴にカプセルが必ず 1 個だけ入るため
の必要条件は，一般的に $\mathrm{A}<\mathrm{a}<2 \mathrm{~A}, \mathrm{~B}<\mathrm{b}<2 \mathrm{~B}$ である と考兄られる。しかし，この条件は不十分である。なぜ なら Bとbの関係において, カプセルはフィーダー落下 穴に斜めに入ることがあり，この場合その上方のカプセ ルとの位置関係は必ずしもフィーダー落下穴の壁に対し 平行ではない，さらにAとаの関係において,フィーダ 一落下穴がカプセル落下穴に一致したとき，aがAに対 して大きすぎるとフィーダーのカッターは上方のカプセ ルをうまく分級できず，回転盤とフィーダー壁との間に カプセルを㣣み込む状態となり，カプセル破損の危険を 招く.

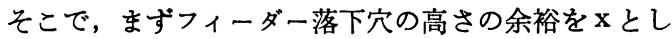
て,フィーダー落下穴を側面および立面から見た状態を 考光，Fig.4 に示した。この場合の $\mathrm{x}$ と Bおよび $\mathrm{b}$ の関 係は,

$$
(b-B)^{2}+(x+B / 2)^{2}=B^{2} \cdots \cdots(1)
$$

で与えられ，式(1)を $\mathrm{x}$ にいて解くと，

$$
\mathrm{x}= \pm \sqrt{2 \mathrm{~b}} \overline{\mathrm{B}-\mathrm{b}^{2}}-\mathrm{B} / 2 \cdots \cdots(2)
$$

を得る.よって，カプセル落下穴で上方のカプセルを分 級し，下方のカプセルを 1 個だけ通過させるには，上方 のカプセルがフィーダー内に入っている高さ $\mathrm{x}$ の範囲と して,

$$
0<\mathrm{x}<\sqrt{2 \mathrm{~b} \mathrm{~B}-\mathrm{b}^{2}}-\mathrm{B} / 2 \cdots \cdots(3)
$$

であることが必要である.

さて式(1)で, $\mathrm{x}=0$ のとき, $\mathrm{b}=(\sqrt{3}+2) \mathrm{B} / 2$ と なるから， bについてはその範囲として次式が与えられ る.

$$
\mathrm{B}<\mathrm{b}<(\sqrt{3}+2) \mathrm{B} / 2 \cdots \cdots(4)
$$

ところがこの時, フィーダー落下穴上方から見た Fig. 4 (II) の状態を考光た場合，条件は式(4)で与兄ら れる範囲では不十分となる.そこで Fig. 4 (II) に示す $2 つ \sigma 円 に$ 外接する点線で描いた正方形を考兄，その辺 B'を求めると,

$$
\mathrm{B}^{\prime}=(\sqrt{6} / 4+1) \mathrm{B} \cdots \cdots(5)
$$

を得る。ゆえにフィーダー落下穴の内径 $\mathrm{b}$ にいての範 囲は次式で与えられよう。

$$
\mathrm{B}<\mathrm{b}<(\sqrt{6} / 4+1) \mathrm{B} \cdots \cdots(6)
$$

つぎに, $\mathrm{x}$ は $a$ の関数として

$$
\mathrm{x}=\mathrm{a}-\mathrm{A} \cdots
$$

でされるから，式(7)を式(3)に代入し，aについて解くと，

$$
\mathrm{A}<\mathrm{a}<\sqrt{2 \mathrm{bB}-\mathrm{b}^{2}}-\mathrm{B} / 2+\mathrm{A}
$$

を得る。この式(8)がフィーダー落下穴の高さ a について の範团を与える。

式(6)，(8)上り A， B を定数と考古， a , b の範囲を求め ると Fig. 5. に示す斜線の領域が得られる.すなわち， 


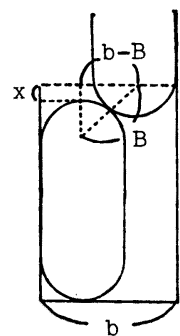

(I)

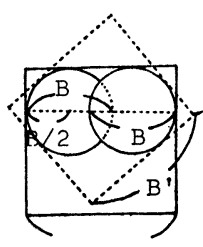

$(\sqrt{3}+2) B / 2$

(II)
Side View

Plane View

Fig. 4. Schematic Diagram of Situation of Two Capsules on the Surface of Drop Hole

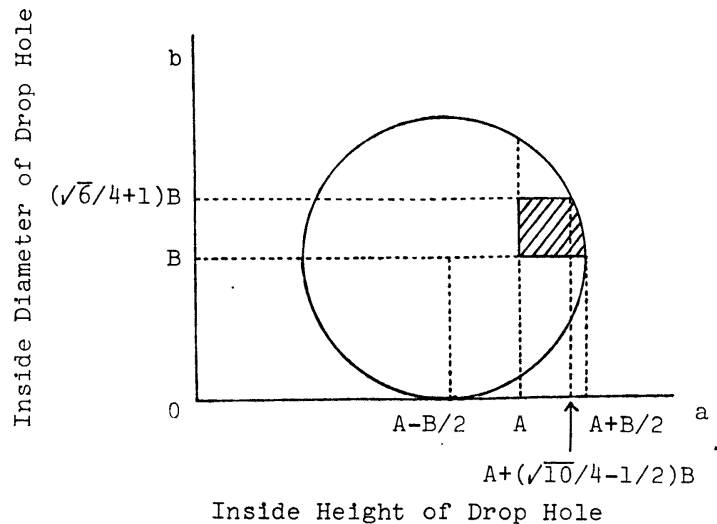

Fig. 5. Size Range of Drop Hole at the Constant SizeValues of Capsules

Capsules Length : A (constant)

Capsules Diameter : B (constant)

Fig.5 はボディーの長さ A , 直径 B のカプセルがどのよ らな寸法のフィーダー落下穴に適合するか，その範用を 示した図である.

\section{3-2. フィーダーに適合するカプセルの大きさの篗囲} の算出

フィーダーの寸法 $\mathrm{a}, \mathrm{b}$ を定数と考え，カプセルの大 きさA，Bについて式(6),(8)を解くと，

$$
\begin{aligned}
& (8-2 \sqrt{6}) \mathrm{b} / 5<\mathrm{B}<\mathrm{b} \cdots \cdots(9) \\
& -\sqrt{2 \mathrm{~b} \mathrm{B-b^{2 }}}+\mathrm{B} / 2+\mathrm{a}<\mathrm{A}<\mathrm{a} \cdots \cdots(10)
\end{aligned}
$$

を得る.これがカプセルボディーの長さ $\mathrm{A}$, 直径 $\mathrm{B}$ につ いての範囲を与える。

式(9),(10)より a， b を定数と考え， A， B の範囲を求め ると Fig. 6 に示す斜線の領域が得られる.すなわち， Fig. 6 は, 高さ a , 内径 bのフィーダー落下穴にどのよ らな大きさのカプセルが適合するか，その範囲を示した 図である。

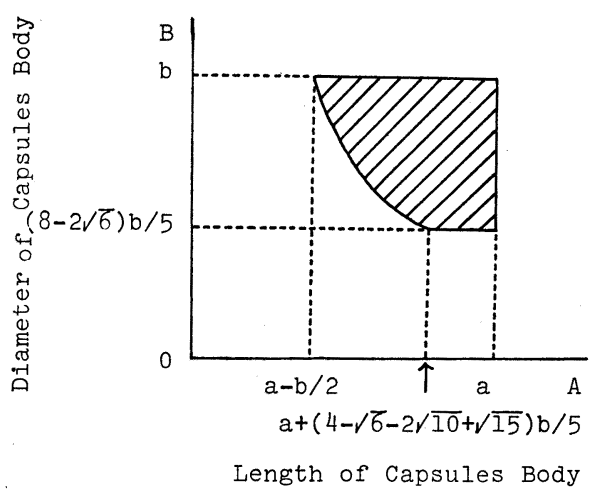

Fig. 6. Size Range of Capsules at the Constant Size Value of Drop Hole Hole Height : a (constant) Hole Diameter : b (constant)

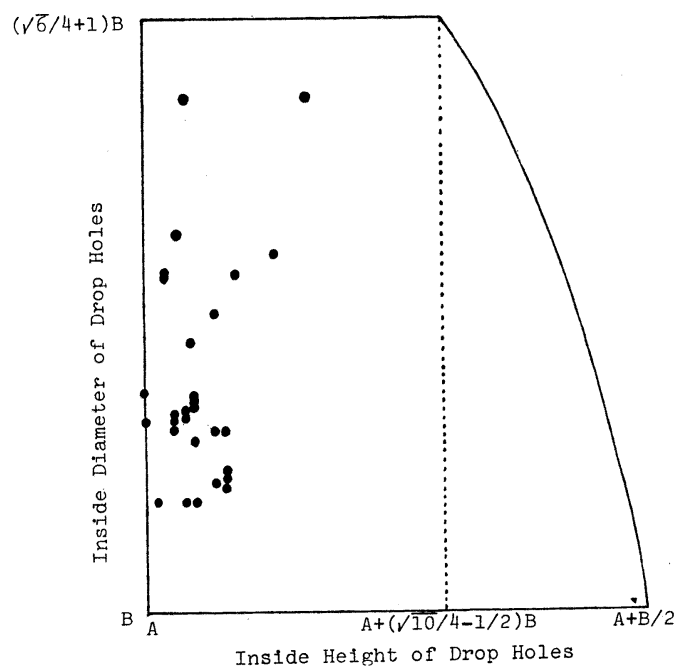

Fig. 7. Relationship between Calculated Size Range and Practical Size of Drop Holes Length of Capsules Body : A Diameter of Capsules Body : B

\section{実験結果と考寮}

Table 1 に市販硬カプセル剂 11 品目をあげ，それぞ れ 10 カプセルの大きさの平均值 $(\overline{\mathrm{x}})$, 標準偏差 (S. D.), 変動係数 (N.S.D.)を示した. さらに推計学的に 計算したそれぞれの寸法範囲 $\left(\mathrm{X}_{\min }, \mathrm{X}_{\max }\right)$ も記載し た.

さらに，おのおののカプセル阂に適合するフィーダー 落下穴の寸法範囲を式(6)，(8)で計算し，Table 2 に示し た. Table 2 の右側の闌には実際に使用しているフィー ダー落下穴の寸法を掲げた。 
Table 1. Size and Size Range of Hard Gelatin Capsule

\begin{tabular}{|c|c|c|c|c|c|c|c|c|c|c|}
\hline Size & \multicolumn{5}{|c|}{ Length } & \multicolumn{5}{|c|}{ Diameter } \\
\hline 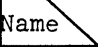 & $\mathrm{Xmin}$. & $X \max$. & $\begin{array}{ll}\bar{X} & \text { a) }\end{array}$ & S.D.b) & N.S.D? & Xmin. & Xmax. & $\overline{\mathrm{X}}^{(2)}$ & S.D. b) & N.S.D. \\
\hline A & 18.55 & 18.73 & 18.64 & 0.032 & 0.172 & $6.5 i$ & 6.79 & 6.65 & 0.053 & 0.797 \\
\hline B & 10.77 & 11.51 & 11.14 & 0.141 & 1.266 & 4.57 & 4.79 & 4.68 & 0.042 & 0.897 \\
\hline C & 15.47 & 15.83 & 15.65 & 0.067 & 0.428 & $5 \cdot 37$ & 5.68 & 5.51 & 0.064 & 1.162 \\
\hline D & 18.71 & 19.07 & 18.89 & 0.067 & 0.355 & 6.10 & 6.28 & 6.19 & 0.032 & 0.517 \\
\hline$E$ & 11.24 & 11.56 & 11.40 & 0.060 & 0.526 & 4.75 & 4.87 & 4.81 & 0.021 & 0.437 \\
\hline$F$ & 15.47 & 16.29 & 15.88 & 0.157 & 0.989 & 5.70 & 5.84 & 5.77 & 0.024 & 0.416 \\
\hline G & 14.08 & 14.68 & $14 \cdot 38$ & 0.114 & 0.793 & 5.18 & 5.30 & 5.24 & 0.021 & 0.401 \\
\hline $\mathrm{H}$ & 13.99 & 14.45 & 14.22 & 0.086 & 0.605 & 5.25 & 5.25 & 5.25 & 0.000 & 0.000 \\
\hline I & $2 i .58$ & 21.98 & 21.78 & 0.075 & 0.344 & $7 \cdot 36$ & 7.64 & 7.50 & 0.053 & 0.707 \\
\hline $\mathrm{J}$ & 17.72 & 17.96 & 17.84 & 0.046 & 0.258 & 6.09 & 6.27 & 6.18 & 0.034 & 0.550 \\
\hline $\mathrm{K}$ & 14.19 & 14.59 & 14.39 & 0.077 & 0.535 & 5.14 & 5.36 & 5.25 & 0.041 & 0.781 \\
\hline
\end{tabular}

a: Average Size of 10 Capsules

unit: $\mathrm{mm}$

b: Standard Deviation

c: Normal Standard Deviation, [N.S.D.= S.D./ $\overline{\mathrm{X}}$ ]

Table 2. Size Range of Drop Hole in Capsule Supply Apparatus

\begin{tabular}{|c|c|c|c|c|c|c|}
\hline \multirow{3}{*}{$\mathrm{N}_{\text {Name }}$} & \multicolumn{3}{|c|}{ Inside Height } & \multicolumn{3}{|c|}{ Inside Diameter } \\
\hline & \multicolumn{2}{|c|}{ Theoretical Value } & \multirow{2}{*}{$\begin{array}{l}\text { Practical } \\
\text { Value }\end{array}$} & \multicolumn{2}{|c|}{ Theoretical value } & \multirow{2}{*}{$\begin{array}{l}\text { Practical } \\
\text { Value }\end{array}$} \\
\hline & Min. & Max. & & Min. & Max. & \\
\hline A & 18.73 & 21.80 & 19.0 & 6.79 & 10.49 & 8.0 \\
\hline B & 11.51 & 13.05 & 12.0 & 4.79 & $7 \cdot 36$ & 7.0 \\
\hline C & 15.83 & 18.14 & 16.0 & 5.68 & 8.61 & 7.0 \\
\hline D & 19.07 & 21.76 & - & 6.28 & 9.83 & - \\
\hline$E$ & 11.57 & 13.61 & - & 4.87 & 7.65 & - \\
\hline$F$ & 16.29 & 18.32 & 16.5 & 5.84 & 9.19 & 7.0 \\
\hline G & 14.68 & 16.67 & & $5 \cdot 30$ & 8.35 & - \\
\hline $\mathrm{H}$ & 14.45 & 16.61 & - & 5.25 & 8.46 & - \\
\hline I & 21.98 & 25.26 & 22.0 & 7.64 & 11.86 & 9.0 \\
\hline $\mathrm{J}$ & 17.96 & 20.76 & - & 6.27 & 9.81 & - \\
\hline $\mathrm{K}$ & 14.59 & 16.76 & 15.0 & 5.36 & 8.28 & 7.0 \\
\hline
\end{tabular}

unit: $\mathrm{mm}$

Table 3. Classified Size Range of Hard Gelatin Capsule and Drop Hole in Capsule Supply Apparatus

\begin{tabular}{|c|c|c|c|c|c|c|c|c|}
\hline & \multicolumn{4}{|c|}{ Capsule } & \multicolumn{4}{|c|}{ Drop Hole } \\
\hline \multirow{2}{*}{ Size } & \multicolumn{2}{|c|}{ Length } & \multicolumn{2}{|c|}{ Diameter } & \multicolumn{2}{|c|}{ Height } & \multicolumn{2}{|c|}{ Diameter } \\
\hline & Min. & Max. & Min. & Max. & Min. & $\operatorname{Max}$ & Min. & Max. \\
\hline I & 10.77 & 11.56 & 4.55 & 4.91 & 11.56 & 13.04 & 4.91 & 7.33 \\
\hline II & 13.99 & 14.68 & 4.99 & 5.36 & 14.68 & 16.48 & $5 \cdot 36$ & 8.04 \\
\hline III & 15.20 & 16.29 & 5.07 & 5.84 & 16.29 & 17.73 & 5.84 & 8.17 \\
\hline IV & 17.07 & 18.07 & 5.92 & 6.36 & 18.07 & 20.03 & 6.36 & 9.54 \\
\hline $\mathrm{V}$ & 18.39 & 19.35 & 6.39 & 6.88 & 19.35 & 21.58 & 6.88 & $10 \cdot 30$ \\
\hline VI & 21.37 & 22.07 & 7.15 & 7.64 & 22.07 & 24.94 & 7.64 & 11.52 \\
\hline
\end{tabular}




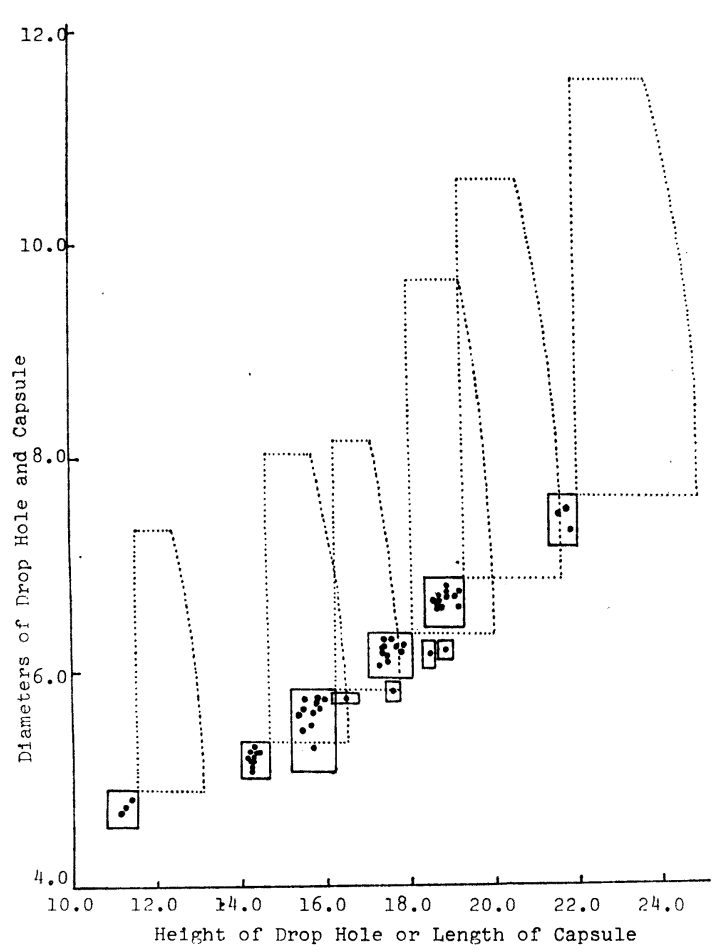

Fig. 8. Relation between the Size of Hard Gelatin Capsule and the Drop Hole in Capsule Supply Apparatus

Size of Hard Gelatin Capsule :

Size Range of Hard Gelatin Capsule :

Size Range of Drop Hole :

理論的に求めたフィーダー落下穴の寸法範围と実際値 の関係を Fig.7 に示した. 実際值は寸法範用内に入っ ており理論值の正しさが実証された。しかし実際値には 大さなバラッキがみられた。

Fig.8 は横軸をカプセルボディーの長さ, 縦軸を直径 として寸法の平均值をプロットしたものである. 実線の ワクで各カプセル剂群の範囲を示した．これより市販硬 カプセル阂は大きく6群に分けられることがわかり, 理 論的解析によりそれぞれの群に対応するフィーダー落下
穴の寸法として点線の 6 群の領域が与えられた。なお， 各群におけるカプセルの大きさと，それに対応するフィ 一ダー落下穴の大きさの範囲を Table 3 に示した.

\section{結論}

今回求めた寸法のフィーダーをあらかじめ作成し，実 際に使用すれば, 現在市販されているカプセル剤に対し より効率のよい確実な分包機能が発揮できるものと思わ れる.また新しいカプセル剂を包装する場合, フィーダ 一の選択が容易となる.さらに現在のところコンピュー ターに登録されていないカプセル剂についても, 先の理 論的解析を導入することで現在使用しているフィーダー が利用でき，経済的にもメリットは大きい.

今後, この種の自動錠剂分包機がさらによい分包機能 を発揮できるよう，錠風・カプセル阂の基礎的な物性と 分包機の機械的特性を関連づけて，実験的考察をすすめ ていくつもりである.

碀辞 終りに，で校閲くださいました東京理科大学薬 学部，小石真純教授に深謝いたします。

文獃

1）沢ノ井政美, 大西昇, 石田定広, 奥田陽子, 三浦 康彦, 平岡栄一：月刊薬事，16(4)，151 (1974).

2) 田中美雄: 医薬ジャーナル, 10(8), 110 (1974).

3）高田勝美, 外間茂吉, 藤下修, 高島忠久: 月刊薬 事, 20 ( 4 ), 77 (1978).

4) 高田勝美, 朝長文弥: 月刊薬事, 21 (4), 161 (1979).

5) 近藤正躬：月刊薬事， 21 ( 8 ), 143 (1979).

6) 門林宗男, 小西清信, 沢ノ井政美, 平岡栄一 : 医 薬ジャーナル, 15 (12), 39 (1979).

7) 桜井喜一監修: “調剤指針注解,”第 2 改訂, 薬事 日報社, 東京, 1978, p.246.

8）高浜弥須夫, 等泰三 : 九州薬学会会報, $25 \cdot 26$, 37 (1972).

9) 諏訪要 : 薬誌, 98,563 (1978).

10) 諏訪要：薬誌, 98, 696, 701 (1978).

11）田島千恵子, 金子重雄, 市原久雄, 杉原正泰 : 病 院薬学, 4(4), 179 (1979). 